\title{
Educating Engineers in Coastal Resiliency with a Global Perspective on Climate Change
}

\section{Dr. Corinna Marie Fleischmann P.E., U.S. Coast Guard Academy}

Commander Corinna Fleischmann is the Program Chair for Civil Engineering at the U.S. Coast Guard Academy. She has a Ph.D. in Civil Engineering from the University of Connecticut, a M.S. in Civil Engineering from the University of Texas, Austin, and a B.S. in Civil Engineering from the U.S. Coast Guard Academy from which she graduated in 1998. She holds a professional engineering license in the state of Florida and a certification as a Certified Sustainable Building Advisor through the National Sustainable Building Advisors Program. CDR Fleischmann joined the faculty at USCGA in 2004 and was selected as a member of the Permanent Commissioned Teaching Staff in 2009. Her research focuses on mitigation of impacts of stormwater in the urban environment and undergraduate engineering education. While at the Academy, she has been an assistant coach on the men's and women's swim teams, faculty affiliate for the women's softball team, advisor for numerous clubs, and a member of the faculty senate. Prior to joining the Coast Guard Academy faculty, CDR Fleischmann was assigned to the U.S. Coast Guard Cutter Elm where she served two tours: as a Deck Watch Officer and Assistant Navigator and as the Operations Officer. In 2001, CDR Fleischmann became a member of the Facilities Engineering Branch at the USCGA. During this tour, she served as both the Safety Officer and the Construction Officer where she was the Contracting Officer's Technical Representative (COTR) as well as Civil Engineering Project Manager for the Academy's \$5.2 million dollar construction program including all aspects of the construction process: cost estimation, general scopes of work, management of change orders and contractor evaluations.

\section{Dr. Hudson V. Jackson, U.S. Coast Guard Academy}

Dr. Jackson received his $\mathrm{PhD}$ from Rutgers University, specializing in Geotechnical Engineering. He is a licensed Professional Engineer with over 30 years of consulting, academic and research experience. He is currently a Professor of Civil Engineering at the United States Coast Guard Academy in New London, CT

Cmdr. Brian Maggi P.E., United States Coast Guard Academy 


\title{
Educating Engineers in Coastal Resiliency with a Global Perspective on Climate Change
}

\begin{abstract}
The future demands civil engineering graduates have an appreciation for the climate-related challenges that lie ahead and that they are exposed to current solutions or, at least, means of mitigation for these anticipated dilemmas. In an effort to educate future civil engineering graduates from the United States Coast Guard Academy (CGA) on the global impacts of climate change, an elective course, Coastal Resiliency was introduced into the curriculum. The objective of the course is to provide exposure to the impacts of climate change and foster a general understanding of the analytical and adaptation methods used to improve the resiliency of civil engineering infrastructure. The course is structured to foster student focused learning by engaging students to research key issues of climate science and engineering adaptation that promotes the development of information literacy skills. The interdisciplinary make-up of the students and term project requirements reinforce the development of teamwork, problem-solving, and communication skills. The use of a variety of learning techniques, and the infusion of global perspectives that includes how different regions of the world are addressing climate change and adaptation planning, has been particularly enriching to the student experience. The authors discuss how CGA has incorporated climate science into engineering education and how the course provides exposure to best practices used in civil engineering to promote infrastructure resiliency in a changing environment.
\end{abstract}

Key words: Climate Education, Civil Engineering, Resiliency

\section{Introduction}

The United States Coast Guard Academy (CGA), located in New London, Connecticut is the smallest of the United States military academies with approximately 1000 cadets and its mission is to educate, train and develop leaders of character who are ethically, intellectually, and professionally prepared to serve their country and humanity. It offers Bachelor of Science degrees in nine majors-including civil engineering and all cadets must graduate in four years. Approximately $12 \%$ of the Class of 2020 are Civil Engineers (typically $10-15 \%$ for any given year). The civil engineering curriculum is broad and provides a solid background in the structures, environmental, geotechnical, and construction sub-fields of civil engineering. Graduates pursue a number of different career paths and many of them serve in the United States Coast Guard (USCG) as practicing civil engineers, pursue professional licensure, and attend graduate programs in civil engineering. Emphasis is placed on balancing theory and practice of engineering, so graduates are intellectually and professionally prepared to provide engineering services to the USCG. Professional skills are particularly reinforced in the engineering courses through laboratory reports, technical papers, presentations, design projects, field trips, interactions with practitioners and USCG officers, community outreach activities, and professional membership. Significant mentoring and advising takes place throughout cadets' years at the Academy which is also an important component for intellectual development and service readiness. The approach of using every opportunity to infuse practical, industrial and USCG relevance into course content has proven successful in fulfilling CGA's mission. 
With increasing evidence of changing climatic conditions, such as increased atmospheric and ocean temperatures, extreme precipitation events, and global sea-level rise, predictions regarding the extent of these effects on engineered systems remain in question. These challenges have positioned the civil engineering community with the task of ensuring that structures can withstand the loading imposed by these previously unaccounted for conditions. From the assessment of the resiliency of coastal infrastructure due to rising sea level to an understanding of the future impacts of forces of nature on our built environment, the importance of educating future generations of engineers with respect to coastal resiliency is becoming increasingly obvious. There are uncertainties in the future levels of greenhouse gases and the predictive models of future climate that make it difficult to define the statistics of future climate and weather extremes [1]. The Intergovernmental Panel on Climate Change (IPCC) concluded that anthropogenic factors play a dominant role in the observed increase in global temperatures [2]. The planning and design of new infrastructure should take into account the future climate to ensure a safe and resilient design. Therefore, it is the responsibility of not only industry, but also of engineering institutions to educate students (future leaders) about the importance of mitigating the impacts of climate change and developing appropriate solutions.

At CGA, the engineering faculty recognize the need to educate the future of our Service and have developed a Coastal Resiliency course that provides exposure into the science of climate change, its impact on civil engineering infrastructure and on the planning and design of resilient structures. The Coastal Resiliency course provides preparation for the real-world practice of engineering by exposing students to the importance of risk and vulnerability assessment within the context of changing climatic conditions. As a sea-going service, the majority of the USCG's assets are along the coastline. As the USCG's primary accession point for civil engineers, ensuring future engineers are exposed to the potential challenges that will likely occur due to rising sea level and other climate-related hazards is an issue of readiness and therefore of the utmost importance. This paper will specifically address manner in which CGA has incorporated climate science into engineering education and provides exposure to best practices used in civil engineering to promote infrastructure resiliency in a changing environment. The future of the USCG and our nation is better served by CGA graduates that have an appreciation for the challenges that lie ahead and are exposed to current solutions or, at least, means of mitigation for these anticipated dilemmas.

\section{The Coastal Resiliency Elective Course}

Coastal Resiliency is currently an elective course that was first offered in spring 2017. The course has become very popular since it was first offered in 2017 to 8 students; there are 31 students enrolled in the course this semester (spring 2020). The make-up of the class is interdisciplinary with students from multiple majors including civil engineering, electrical engineering, marine science, naval architecture, and the term project includes collaboration with students from humanities. This course addresses ways of incorporating climate science into engineering and provides exposure to best practices used in the civil engineering community to promote infrastructure resiliency in a changing climate. Emphasis on the importance of risk and vulnerability assessments of facilities and communities in dynamic environments prepares cadets for the real-world practice of engineering and highlights the exciting but challenging opportunities that lie ahead in their careers. The course objectives are as follows: 
- Provide exposure and foster general understanding of analytical methods used to update and describe climate for planning and civil engineering design.

- Identify methods of assessing the impacts and vulnerabilities caused by changing climate conditions.

- Discuss best practices in civil engineering related to climate change and infrastructure resiliency, especially practical methods to improve infrastructure resiliency.

- Discuss the Coast Guard's initiatives and approach to reducing risk and ensuring that shore assets are resilient.

- Provide understanding of basic waterfront facilities inspection and assessment practices.

\section{Pedagogical Approach and Course Delivery}

The intersection of engineering and social science where natural hazards occur has become a significant component of vulnerability assessments and the development of resilient engineering solutions for communities and federal facilities. This can be seen in the American Society of Civil Engineers (ASCE) Natural Hazards Review [3], "The 2017 Disasters: Sociotechnical Perspectives" and various resilience master planning reports which incorporate numerous stakeholder meetings to brainstorm engineered solutions that are economically and socially viable. It's this sociotechnical approach that the diverse group of faculty leading this course have taken to develop the Coastal Resiliency course. With civilian and military backgrounds in the environmental and geotechnical sub-disciplines of civil engineering, the course coordinators' experience in consulting, academics, research, facility engineering, design and construction management, disaster response to restore operations for impacted USCG facilities, and service aboard multiple USCG Cutters has led to the development of this civil engineering centric, multidisciplinary course. Guest speakers from the humanities department provide background on how policies impact vulnerabilities and affect coastal planning. CGA's Institute for Leadership also coordinates former Commandant of the USCG, Admiral Thad Allen, as a guest speaker whose transparent stance on climate change, more specifically sea level rise, reiterates the importance of the course for the cadets. Throughout the course, emphasis is placed on diverse global perspectives that include incorporating science, policy, community awareness and engagement into engineered solutions.

As previously mentioned, the class consisted of a mix of students (juniors and seniors) with different backgrounds and from four different majors. To make the course engaging and facilitate student learning at higher levels, several pedagogical tools are used in addition to the typical white board and PowerPoint. Some examples of other media and techniques used include:

- Computer simulations and software packages - There are several computer simulations that have been very useful especially for the visual learners. These include simulations of climate models that predict or show the effects of sea-level rise, examples include:

- NOAA's Sea Level Rise Map Viewer - an open source web mapping tool used to visualize community-level impacts from coastal flooding or sea level rise (up to 10 feet above average high tides). Photo simulations of how future flooding might impact local landmarks are also provided, as well as data related to water depth, connectivity, flood frequency, socio-economic vulnerability, wetland loss and migration, and mapping confidence. 
- Surging Seas by Climate Central Risk Finder - provides PDF downloads that summarize key information for a selected area. Customizable slides, maps and data downloads to assist in visualizing sea level rise are also available.

- Sea, Lake, and Overland Surges from Hurricanes (SLOSH) model - a numerical model sponsored by the National Weather Service that can estimate storm surge heights.

- USGS Coastal Storm Modeling System (CoSMos) - a tool "developed for hindcast studies, operational applications and future climate scenarios to provide emergency responders and coastal planners with critical storm-hazard information to improve public safety, mitigate damages and more effectively manage and allocate resources. " [4]

- U.S. Army Corps of Engineers (USACE) North Atlantic Coast Comprehensive Study (NACCS) - a tool that builds on lessons learned from Hurricane Sandy "to help local communities better understand changing flood risks associated with climate change and to provide tools to help those communities better prepare for future flood risks."[5]

- Animations and Movies - Several animations and movies about the impact of greenhouse gases on climate and temperature are used to demonstrate key concepts and foster discussions on the issues. Examples of animations and movies include:

- Atmospheric Energy Balance (Prentice Hall, Inc)

- Climate Change 101 with Bill Nye (National Geographic)

- Shored-up, a film by Ben Kalina, that documents the impact of Hurricane Sandy on NY and a summary of the US Army Corp of Engineers beach replenishment policies as well as some socio-economic aspects of disaster relief and management.

- Age of Consequence, an Emmy nominated film by P.F. Pictures, which highlights the potential impact of climate change on national security, military deployment, global unrest and global security.

- Hands-on activities - The term project requirement is a significant part of the course. Faculty continue to revise this requirement to consistently foster diversity and inclusion in completing this assignment. Several team building exercises, especially enhancing team cohesion and team interview skills, are included in the course. The site visit component involves having students see the project challenges firsthand, collect measurements and photos, and interact with project sponsors and the local community. The role playing exercise described below can also be considered a hands-on activity.

- Role Playing - Students are required to work in groups of 3-4 to represent different world regions (Southern Asia, Central Asia, Australia, South America, Western Europe, and Russia) seeking international aid from the United Nations (UN) for use to mitigate shortterm resiliency issues related to climate change. Students research their selected region for any pressing climate-related issues and come up with a proposal to improve resiliency to those hazards. Students play the roles of regional representative to the UN to present their proposal as they compete for the aid. Only one region can be awarded the aid, so the arguments have to be convincing to a panel of faculty who serve as UN officials.

- Student led discussions - There are multiple opportunities embedded in the course for students to research a topic and lead class discussions or make presentations to the class. Some examples include researching and making presentations on climate proxies, leading 
weekly discussions on contemporary issues, risk and vulnerability assessments of several civil engineering sectors and a role playing exercise as previously described.

- Emphasis on practical applications and relevance to local community - The term project is a key component of the course and is described in the next section. Students are encouraged to be engaged in assessing the diverse perspectives on the issues including incorporating science into engineering solutions, policy, and community awareness and engagement. Their proposed solutions must be relevant and compatible to the local community they are trying to serve.

- Case Studies - These include the impacts of climate change on infrastructure and communities (i.e. hurricanes, drought, flooding, wildfires, etc.), global engineering solutions, ongoing research on soft and hard coastal engineering solutions, and current challenges for Coast Guard facilities. A couple of specific examples include:

○ Geosynthetic Reinforced Dunes in Montauk, NY: A USACE stabilization project more than $0.6-$ mile $(1-\mathrm{km})$ long and consisting of more than 11,000 geosynthetic sand containers to reinforce the core of dunes, which are then reconstructed along with the placement of a protective berm. Surveys performed using RTK differential GPS, Structure-From-Motion photogrammetry using an Unmanned Aerial System (UAS), and boat-mounted LiDAR and interferometric sonar are all discussed as modern tools used to observe the impacts of chronic climate and acute weather event impacts on the erosion and deposition of sand at the site, Figure 1 [6].

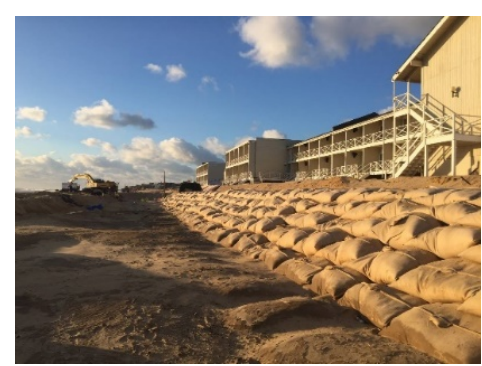

(a)

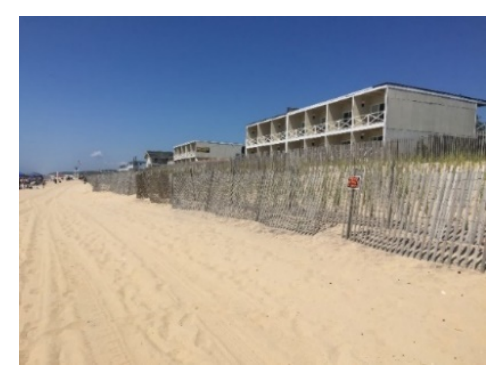

(b)

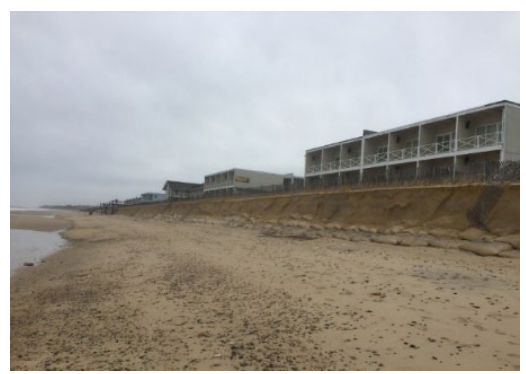

(c)

Figure 1. (a) USACE stabilization project during construction (Photo Credit: First Coastal Corporation), (b) As-built condition of the site in June 2016, (c) Post nor'easter erosion assessment in January 2017. 
- USCG Station Brant Point, Nantucket, MA: Many of the Coast Guard's facilities are vulnerable to flooding, especially many of the older, historic facilities in New England. Station Brant Point is presented as an example where the increased frequency of tidal flooding and storm induced flooding negatively impacts mission readiness and response, Figure 2.
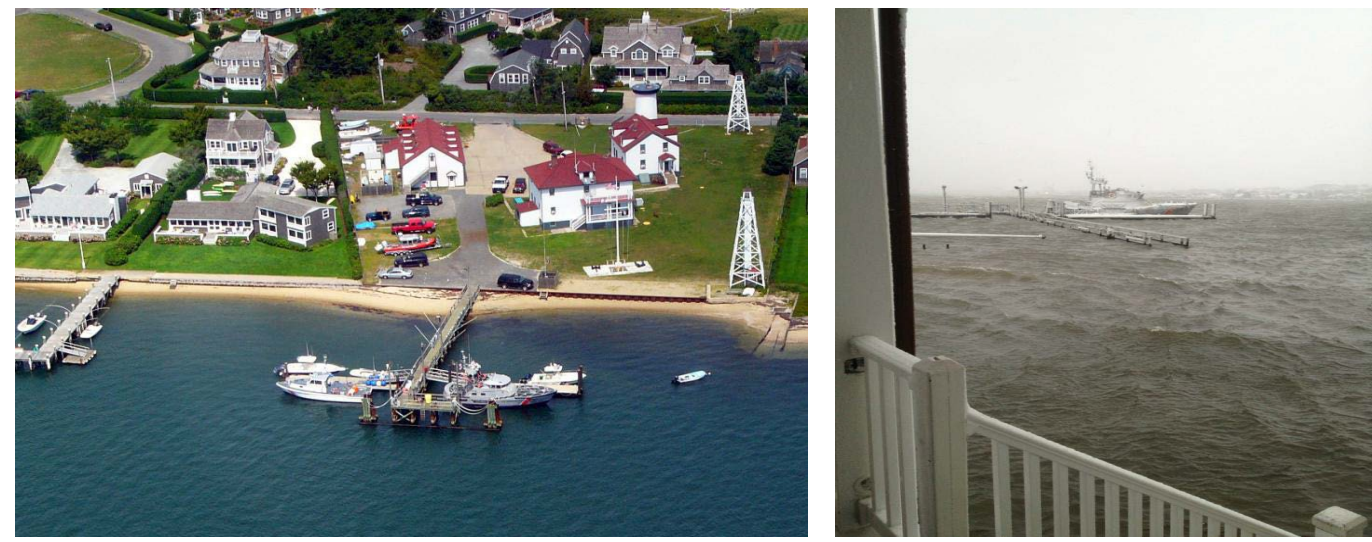

Figure 2. USCG Station Brant Point and flooding that occurred during Winter Storm Juno, January 2015.

\section{Examples of Course Content/Presentation}

As an elective course designed for civil engineers, but taken by engineers of other disciplines and marine science majors, the course is intentionally not heavy in civil engineering design. Instead, the course was created to be engineering focused, but at a level that any student with basic science and management knowledge could participate. Students are provided the course textbook, ASCE's Committee on Adaptation to a Changing Climate's Adapting Infrastructure and Civil Engineering Practice to a Changing Climate [7] to assist in their understanding of the civil engineering principles and components addressed in the course. A summary of the key modules in the course is presented in Table 1.

Table 1: Summary of Key Course Content

\begin{tabular}{|c|c|}
\hline Module & Objectives \\
\hline Climate Science & $\begin{array}{l}\text { Discuss factors that drive climate change } \\
\text { - } \\
\text { Provide an overview on supporting data on } \\
\text { climate change } \\
\text { Introduce IPCC and its role in } \\
\text { documenting/investigating climate change }\end{array}$ \\
\hline Climate Proxies & $\begin{array}{l}\text { Discuss the science of documenting and } \\
\text { investigating changes in climate } \\
\text { Briefly introduce associated proxies used to } \\
\text { evaluate past climate patterns }\end{array}$ \\
\hline $\begin{array}{l}\text { Climate Mechanisms and } \\
\text { Models }\end{array}$ & $\begin{array}{l}\text { Discuss the natural and human factors } \\
\text { contributing to climate change } \\
\text { Briefly introduce a variety of Global Climate } \\
\text { Models, Earth System Models and regional } \\
\text { models used to predict climate change and } \\
\text { potential impacts }\end{array}$ \\
\hline
\end{tabular}




\begin{tabular}{|c|c|}
\hline Module & Objectives \\
\hline Framework for Resiliency & $\begin{array}{l}\text { - } \quad \text { Discuss basic definitions of resiliency } \\
\text { Expose students to the various categories of } \\
\text { resiliency (Engineering, Ecological, } \\
\text { Community) }\end{array}$ \\
\hline Risk Assessment & $\begin{array}{l}\text { - Provide a framework to define risk } \\
\text { - Provide an overview on the risk distribution in } \\
\text { coastal areas in the U.S. } \\
\text { Discuss methods of risk and vulnerability } \\
\text { assessment }\end{array}$ \\
\hline $\begin{array}{l}\text { CE Infrastructure } \\
\text { Challenges }\end{array}$ & 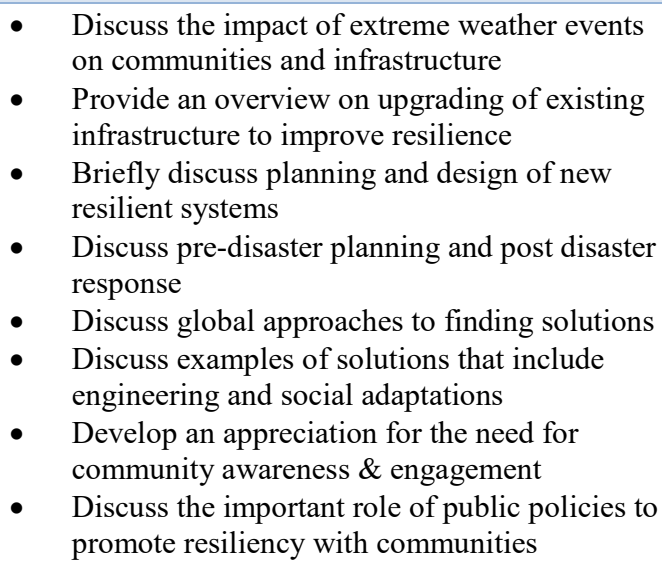 \\
\hline Case Studies & $\begin{array}{l}\text { - Foster discussion and provide additional } \\
\text { background of concepts and principles } \\
\text { - Illustrate practical examples of concepts and } \\
\text { principles }\end{array}$ \\
\hline Term Project & $\begin{array}{l}\text { - } \\
\text { - } \\
\text { Derform vulnerability and risk assessment } \\
\text { improve resiliency to climate related hazards } \\
\text { Foster interaction with residents in local } \\
\text { community } \\
\text { Develop an appreciation of the socioeconomic } \\
\text { impact of climate hazards on local community } \\
\text { Develop team building skills and an } \\
\text { appreciation of diverse perspectives within } \\
\text { teams }\end{array}$ \\
\hline
\end{tabular}

\section{Term Project}

The course includes a term project that requires students to perform a risk and vulnerability assessment due to climate change, within the local community or at a USCG facility. The focus of the project is to relate practical applications of sustainability, scientific, and engineering principles to address the challenges of infrastructure resiliency within the context of changing climatic conditions. Over the past three years, significant changes have been made to the term project requirement. For the first three iterations of the course, all students assessed the same location; an active USCG Station (year 1), the CGA waterfront (year 2) and a USCG test facility in Mobile Bay, Alabama (year 3). These first three projects were all USCG units and did not provide the students opportunities to work with local communities. Before the spring 2020 offering of the course, instructors established partnerships with local and state officials to 
develop a list of local community projects. Project stakeholders were invited to present their project(s) to the students. Students were required to work in groups of four. Projects were assigned based on interest, with priority given to ensuring teams were interdisciplinary. Collaboration was also established with the humanities department by having a group of their students work on policy and governance related aspects of one or more of the projects. The objectives of completing the project are to:

- Perform a vulnerability assessment or suitable assessment tailored to meet the communities' stated needs.

- Develop and identify potential solutions that support long-term community goals and improve resiliency to hazards caused by changing climatic conditions.

The spring 2020 projects include:

1. Waterford/Niantic, CT Watershed Infrastructure Resilience The Climate Change Risk Vulnerability, Risk Assessment and Adaptation Study for Waterford completed in November 2017 identified infrastructure vulnerabilities and adaptation strategies for areas along Niantic River Road. This project will involve a review of the study and other documents identified in the literature review, engagement of community and potential grant partners to validate the assessment, identification of potential failure points, analysis of proposed design options, and development of a resiliency plan with prioritized recommendations focusing on infrastructure projects along Niantic River Road and adjacent sites.

2. Waterford/Niantic, CT Watershed Environmental Resilience

A Niantic River Resilience Vision, developed by The Nature Conservancy and published in March 2017, provides initial analysis and design recommendations that identifies vulnerabilities along with potential solutions. Additional information is provided in the Climate Change Risk Vulnerability, Risk Assessment and Adaptation Study for Waterford completed in November 2017. This project will involve an environmental and stormwater assessment of the potential impacts of climate change and extreme weather events on the Niantic River Watershed as a natural and economic resource, engagement with the Niantic River Watershed Committee, Nature Conservancy and other environmental stakeholders, and development of a management plan with prioritized action items to protect the natural resources of the Niantic River Watershed.

3. Waterford, CT Extreme Event Recovery

The Climate Change Risk Vulnerability, Risk Assessment and Adaptation Study for Waterford completed in November 2017 identified vulnerabilities in emergency response and recovery operations. Recovery plans following an extreme event are not thoroughly developed to promote long-term community resilience and typically result in the restoration of pre-event, vulnerable conditions. This project, focused on disaster recovery, will involve a review of the study and other documents identified in the literature review, engagement with emergency management coordinators, and development of a multi-stage (i.e. immediate to long-term) recovery plan for transportation and other critical infrastructure that is sustainable and adds resilience to these systems during recovery from an extreme event. 
4. Mystic Seaport, CT Infrastructure Resilience

Founded in 1929, Mystic Seaport is extremely vulnerable to climate change and sea level rise as documented in assessment reports and regular observations during storms and significant high tide events. This project will involve a review of previous assessments for the Seaport and Mystic River along with other documents identified in the literature review, engagement with Seaport stakeholders to validate the literature review findings, identification of critical vulnerabilities, and development of resilient solutions with prioritized recommendations.

\section{City of Groton, CT Pollution Abatement Facility (PAF) Resilience}

The PAF is Groton Utilities' sewerage treatment plant serving the City of Groton, Town of Groton, and other nearby customers. During rain events, flows increase because of infiltration of rainwater into the collection system. The facility is vulnerable to flooding during extreme events and potential sea level rise. Siting of the facility is also an issue since it's located within a residential/mixed use coastal historic area. This project will involve an assessment of the potential impacts of climate change and extreme weather events on the PAF, a review of city and state coastal development regulations, engagement with City and Groton Utilities stakeholders, and the development of a resiliency plan which includes both short and long term recommendations.

\section{City of Groton, CT Future Floodplain Limit Analysis}

Based upon the City of Groton's research, no mapping has been completed to understand the implications of sea level rise on the various flood plain areas. Considering the City's coastal vulnerabilities, this project will determine how sea level rise will impact flood zone limits by conducting desktop surveys, field validations, a literature review of FEMA flood zone regulations and NOAA sea level rise projections, and environmental and city stakeholder interviews to develop recommendations on how different levels of sea level rise will affect the City's coastal zones in 2050 and 2075.

7. City of Groton, Eastern Point Historic District Resilience

Eastern Point Historic District is located in the southwestern portion of the City of Groton at the mouth of the Thames River. A substantial portion of the District is within the flood zone and Shore Avenue is vulnerable to flood events. This project will involve an assessment of the potential impacts of climate change and extreme weather events on the Historic District, a review of State Historic Preservation regulations along with a literature review, engagement with City and State Historic Preservation Office stakeholders, and the development of a community resiliency plan for the District which includes both short and long term recommendations.

\section{City of Groton, CT Economic Development}

City of Groton Economic Development stakeholders will pursue public engagement to improve community understanding of the potential impacts of climate change and sea level rise along with adaptation strategies to support the City's Economic Development. This project will involve a vulnerability assessment of the economic district, engagement with City and business stakeholders, an economic impact analysis of the potential 
impacts of climate change and extreme weather events, and the development of a business continuity plan along with outreach tools to improve the resilience of local businesses.

Deliverables for the term project include a brief report and an oral presentation to community stakeholders. Students are expected to focus on the practical application of scientific and engineering principles to address the challenges of infrastructure and community resiliency within the context of changing climatic conditions. The key components should encompass the assessment of the risk and vulnerabilities involved with maintaining status quo; development of engineering solutions to improve the resiliency of community assets; and if appropriate, recommendations for further research or support for resilient stewardship of the issues into the future.

\section{Enhancing the Student Experience}

The course is structured to foster student focused learning by engaging students to research key issues of climate science and engineering adaptation that promotes the development of information literacy skills. The infusion of global perspectives that includes how different regions of the world are addressing climate change and adaptation planning has been particularly enriching to the student experience. As stated by Bill Nye, "the science of climate change is easy: burning fossil fuels creates greenhouse gasses that are warming our world... the hard part: connecting the wellhead to the tailpipe in people's minds as soon as possible" Bill Nye [8]. Familiarizing students with what is being done on a global scale broadens their perspective and helps to build consensus that a global-community approach is required to urgently address the challenges of climate change. In addition, the interdisciplinary make-up of the students and term project requirements reinforce the development of teamwork, problem-solving, and communication skills. Interaction with project sponsors who are excited to work with students generates enthusiasm and a sense of adding value to the local communities. The urgency of the issues, associated challenges and direct connection to impacts on a community motivates and empowers student to make a difference through the engagement in lifelong learning.

\section{Assessment and Course Improvements}

As previously mentioned, the course was first offered in 2017. Over the past three years, several modifications have been made due to student feedback, instructor assessment of the course content and evolution of fundamental research linking climate change to coastal resiliency. Assessment results and subsequent course changes include:

\section{$\underline{\text { Review of } 2017 \text { Course offering }}$}

In 2017, the course was offered to eight civil engineering students. The requirements included the completion of two mini projects. The first project was an assessment of the vulnerabilities of several facility assets on campus; the second project was a detailed risk and vulnerability assessment of a local USCG Station in New London, CT. Emphasis was placed on the civil engineering approaches to improving resilience. Students also had the opportunity to visit the U.S. Army Corps of Engineers Cold Regions Lab in New Hampshire.

Assessment: Overall, the reviews and feedback of the course were overwhelmingly positive. Students loved the discussion-based structure of the course, guest speakers and multiple instructors. They indicated that the different teaching styles and perspectives enriched their 
learning experience. Student did feel that the course was too heavy on climate science and on risk assessment. The climate science module was delivered by a professor from the Science Department. Suggestions from students regarding the presentation of weekly current events and more examples of global solutions were identified as good opportunities to improve the 2018 course offering. While students also requested more field trips, this suggestion was noted but had to be reevaluated in each future course offering because of the already limited amount of time in class due to other demands on military student, or cadet, schedules.

\section{$\underline{\text { Review of } 2018 \text { Course offering }}$}

Ten students from two engineering majors took the course in 2018. In response to students' feedback and evaluation of the 2017 course offering, the following changes were made:

- Reduction of the climate science module. The objective was to provide breadth or a more general overview. This module was taught by one of the civil engineering faculty instead of a faculty member from the Science Department.

- Addition of another module that deals with climate change as a driver for world conflict and how this would affect military missions and foreign policy.

- Incorporation of various media such as videos and movies

Assessment: While the students liked presenting on current event articles, they did find the required readings from the text hard to digest. The additional feedback that was not duplicative from the previous course offering included suggestions to modify the second project to provide a more diverse perspective of vulnerability issues beyond a local USCG Station. Additionally, more exposure to resiliency policies and standards for the USCG and national/state levels was requested.

\section{$\underline{\text { Review of } 2019 \text { Course offering }}$}

Thirteen students from four different majors (Civil Engineering, Marine and Environmental Science, Naval Engineering and Marine Architecture, and Mechanical Engineering) took the course. The 2019 course offering included significant changes in response to the lessons learned from 2017 and 2018. The changes made to improve student learning and the restructuring implemented to make the course more appealing to non-civil engineering students included:

- Placing more emphasis on the general global debate of climate change stressors

- Incorporating a variety of innovative teaching techniques such as short videos, more frequent current event discussions, hands-on team building exercises, and the collaboration of three faculty members to present course material throughout the semester

- Working in partnership with the USCG Research and Development Center (CG-RDC) to investigate the vulnerability of a USCG island facility in Mobile, AL to climate induced erosion. This assignment was used as the term project requirement.

- The target audience, up to the 2019 offering, was senior level students. At CGA, students find out their "billet" (their duty station for at least the next two years) in March. After they learn of their assignment, they were tasked with researching and presenting to the class resiliency efforts and challenges in what would soon be their new home. This assignment was very well received by students as they were preparing to move to another part of the country. 
- Course content was restructured and flow revised. Students were given more short reading assignments to facilitate class discussions; most of the discussions were student led.

Assessment: One of the biggest lessons learned is the strong student desire for a site visit where students have the opportunity to physically see the mitigation measures or resiliency issues discussed in the course. The term project site was in Alabama; due to USCG travel and funding restrictions and the number of students in the course, it was not feasible to visit the site.

Additionally, a more local field trip was planned for the course, but logistically it did not work out either. In 2019, there were no on-site visits. For the 2019 offering of the course, students also expressed the desire to be more engaged and exposed to the debate on the impact of climate change. To satisfy this request, the course instructors worked with other academic majors to more aggressively advertise the interdisciplinary nature of the course to other majors. This effort proved successful as students from multiple majors signed up for the 2020 offering of the course.

\section{Preliminary Review of Current Course offering}

One of the most significant changes in the 2020 offering is the inclusion of multiple projects in the local community as previously discussed. Preliminary mid-term assessment indicated that students felt overwhelmed about the project and concerned that the workload is too much. The interdisciplinary make-up of the team has led to complications in scheduling site visits and team meetings. To alleviate this and based on student feedback, the schedule was revised to include one project work day each week as well as additional interim assignments to ensure that students are making the required progress. Specifically, the students, who were working on capstone projects in their various majors, felt that this was a second capstone. While that was absolutely not the intention of the course instructors, this was a comment that came up in many of the cadet midterm feedback forms.

The course instructors also learned at midterm that the students were largely uncertain about how to approach a large scale, community issue that was not a straight forward engineering design. This absence of specific instructions on how to proceed created a great deal of angst and hindered progress. As instructors, while the intent was not to increase their anxiety, the openended problem presented by the local resiliency projects did make them all uncomfortable. Adding to that stress, each small group had a different project and therefore, they could not look to another group to ensure they were on the "right track". As instructors, we had to slow down the pace of the course to help guide them through this discomfort and to ensure that the project deliverables will meet stakeholders' expectations. The instructors believe that there was real growth in this discomfort and that, for the future, these students have a better understanding of how to navigate engineering projects developed to address community challenges.

\section{Conclusions}

From the assessment of the resiliency of coastal infrastructure due to rising sea level to an understanding of the future impacts of forces of nature on our built environment, the importance of educating future generations of engineers with respect to coastal resiliency is becoming increasingly obvious. The future demands civil engineering graduates have an appreciation for the climate-related challenges that lie ahead and that they are exposed to current solutions or, at least, means of mitigation for these anticipated dilemmas. In an effort to educate future civil engineering graduates from CGA on the global impacts of climate change, an elective course, 
Coastal Resiliency was introduced into the curriculum. The objective of the course is to provide exposure to the impacts of climate change and foster a general understanding of the analytical and adaptation methods used to improve the resiliency of civil engineering infrastructure. Several pedagogical tools such as videos, role-playing, case studies and project-based learning are used to foster student learning of the key principles and concepts. There is a strong emphasis on global perspectives to addressing the impact and challenges resulting from changing climatic conditions to ensure students understand the complexity and consequences. The term project assignment provides students an opportunity to see this firsthand through the completion of risk and vulnerability assessments that lead to the development of sustainable solutions to improve the resiliency in several local communities. Assessment data for the 2020 spring semester are not yet available, however student feedback from previous course offerings has been very favorable leading to the significant surge in enrollment. The majority of student feedback is centered around prior offerings, former versions of the term project, and on lessons learned. However, preliminary assessment data for spring 2020 indicate that students continue to enjoy the interdisciplinary nature of the course, but struggle with the open-ended nature of the multiple term projects. While the relevance of this course at CGA is clear given the mission of the USCG and the future impact climate change will have on Service missions, the broader impacts it has on local communities and awareness students have as future engineering leaders make it a relevant elective course for any civil engineering undergraduate curriculum.

\section{References}

[1] American Society of Civil Engineers (ASCE) Committee on Adaptation to a Changing Climate, "Climate-Resilient Infrastructure," ASCE Manual and Report on Engineering Practice No. 140, ASCE, Reston, VA, 2018.

[2] M. R. Allen et al, "Special Report: Global Warming of $1.5^{\circ} \mathrm{C}$," The Intergovernmental Panel on Climate Change, October 2018.

[3] N. Uddin and L. K. Comfort, "American Society of Civil Engineers (ASCE) Natural Hazards Review," Volume 20, Issue 3, August 2019.

[4] United States Geological Survey (USGS) website, https:/www.usgs.gov/centers/pcmsc/science/coastal-storm-modeling-system-cosmos?qt$\underline{\text { science }}$ center_objects $=0 \#$ qt-science center_objects

[5] United States Army Corp of Engineers (USACE) website, https://www.nad.usace.army.mil/CompStudy/

[6] B. Maggi, C. D. P Baxter, A. Bradshaw, A. Grilli, and N. Al Naser, "Reinforcing dunes and bluffs with geosynthetics," Geosynthetics, Volume 37, Number 5, October/November 2019.

[7] ASCE Committee on Adaption to a Changing Climate, Adapting Infrastructure and Civil Engineering Practice to a Changing Climate, ASCE, Reston, VA, 2015.

[8] G. Marshall, Don't Even Think About It: Why Our Brains Are Wired to Ignore Climate Change. New York, NY: Bloomsbury, 2014. 